Editorial

\title{
Mestrado Profissional em Climatologia e Aplicações nos Países da CPLP e África
}

Em maio de 2015 na Cidade da Praia - Ilha de Santiago em Cabo Verde foi constituído o Centro de Investigação Climática e Aplicações nos Países da CPLP e África (CIICLAA). Este centro congrega várias instituições de ensino e pesquisa, mais centros operacionais de meteorologia da Comunidade dos Países de Língua Portuguesa (CPLP). Na ocasião, a Universidade Estadual do Ceará (UECE) - Membro Fundador do CIICLAA e com cadeira no Conselho Científico recebeu a missão de formação, e assim, no ano seguinte (2016) conseguiu aprovar em chamada pública da Coordenação de Aperfeiçoamento de Pessoal de Nível Superior (CAPES) o Curso de Mestrado Profissional em Climatologia e Aplicações na CPLP e África (MPClimatologia) que foi implantado no Campus do Itaperi em Fortaleza/CE..

O MPClimatologia tem como objetivo promover pesquisa e desenvolvimento, com caráter interdisciplinar, relacionados ao clima e suas variabilidades, bem como gerar aplicações dos resultados obtidos para produzir produtos ou processos inovadores do uso das informações meteorológicas, que possam subsidiar a elaboração de políticas públicas e tomada de decisão, visando contribuir para a melhoria da realidade sócio-econômico-ambiental dos países membros da CPLP e África - membros fundadores do CIICLAA.

Com início em julho de 2016, o curso formou em sua primeira turma 28 (vinte e oito) egressos e para comemorar o sucesso de implantação e cumprimento da missão de formação assumido com o CIICLAA, firmou parceria com a Revista Brasileira de Meteorologia (RBMET) da Sociedade Brasileira de Meteorologia (SBMET) para a publicação de número especial de comemoração do MPClimatologia.

Ressalta-se que os artigos publicados no número especial, primeiro, foram selecionados em edital por uma comissão de seleção composta por docentes colaboradores do curso. Após essa fase de seleção, a avaliação dos artigos seguiu o processo de publicação da RBMET, e assim, foram encaminhados aos editores e avaliadores Ad hoc por meio da plataforma ScholarOne ${ }^{\circledR}$ do portal da Scielo ${ }^{\circledR}$.

Nesta edição especial da RBMET são publicados dez artigos que apresentam resultados das pesquisas realizadas e dissertações concluídas no MPClimatologia, estudos interdisciplinares que abordam questões relacionadas a climatologia e os cenários de influência das mudanças climáticas na saúde, na agricultura, nos recursos energéticos renováveis e nas ações de defesa civil.

Prof. Dr. Emerson Mariano da Silva iD Coordenador do MPClimatologia Departamento de Física, Universidade Estadual do Ceará, Fortaleza, CE, Brasil.

Recebido em 1 de Outubro de 2019 Aceito em 1 de Outubro de 2019

Autor de correspondência: Emerson Mariano da Silva, emerson.mariano@uece.br. All the contents of this journal, except where otherwise noted, is licensed under a Creative Commons Attribution License CC-BY. 